\title{
Continuous-flow biventricular mechanical support implantation strategies
}

\author{
Jaime-Jürgen Eulert-Grehn ${ }^{1,2}$, Pia Lanmüller ${ }^{1,2}$, Christoph Starck ${ }^{1,2}$, Felix Hennig ${ }^{1,2}$, Stephan Jacobs ${ }^{1,2}$, \\ Volkmar Falk ${ }^{1,2,3,4}$, Evgenij Potapov ${ }^{1,2}$ \\ ${ }^{1}$ Department of Cardiothoracic and Vascular Surgery, German Heart Center Berlin, Berlin, Germany; ${ }^{2}$ DZHK (German Center for Cardiovascular \\ Research), Partner Site, Berlin, Germany; ${ }^{3}$ Department of Cardiothoracic Surgery, Charité-Universitätsmedizin Berlin, Corporate Member of Freie \\ Universität Berlin, Humboldt-Universität Berlin, and Berlin Institute of Health, Berlin, Germany; ${ }^{4}$ Department of Health Sciences, ETH Zurich, \\ Translational Cardiovascular Technologies, Zurich, Switzerland \\ Correspondence to: Jaime-Jürgen Eulert-Grehn. Department of Cardiothoracic and Vascular Surgery, German Heart Center Berlin, Augustenburger \\ Platz 1, 13353 Berlin, Germany. Email: jeulert@dhzb.de.
}

Submitted Apr 28, 2021. Accepted for publication May 24, 2021.

doi: 10.21037/acs-2021-cfmcs-36

View this article at: http://dx.doi.org/10.21037/acs-2021-cfmcs-36

\section{Clinical vignette}

A 51-year-old patient with ischemic cardiomyopathy implanted with a continuous-flow left ventricular assist device (cfLVAD) presented with persistent right ventricular (RV) failure. After stabilizing the patient, implantation of a continuous-flow RV assist device (cfRVAD) was performed.

\section{Surgical techniques}

\section{Preparation}

Preoperative chest CT is essential for procedural planning; for example cannulation strategies in redo-procedures, detection of shunts or semilunar valvular insufficiency and to accommodate the implant strategy to the intrathoracic dimensions (pump choice and implant site: right atrial or ventricular). The cfRVAD inflow cannula can be implanted into the right atrium or ventricle. Therefore, pacemaker and Implantable Cardioverter Defibrillator leads should be explanted prior.

\section{Exposure}

In case of adhesions we recommend leaving the pericardium on the right atrial wall. Close attention must be paid to the phrenic nerve.

\section{Surgical procedure}

The pulmonary trunk, right atrium and LVAD outflow tract were freed from adhesions to ensure adequate exposure.

Next, the inflow ring is adapted to the thin wall of the right atrium by augmentation with Teflon rings for extraluminal height reduction. We used seven Teflon strips due to right atrial enlargement. These Teflon strips were glued together (Bioglue, CryoLife, Georgia, USA). Subsequently we create a hole in the inner circle using the cutting knife of the HeartMate3 (Abbott Laboratories, Illinois, USA) system package which has the same internal diameter as the HeartWare (Medtronic, Dublin, Ireland).

Under transesophageal echocardiography guidance, the correct position at the right atrial free wall is located, ensuring sufficient distance to the inferior vena cava and heading towards the middle of the tricuspid valve. In standard fashion, two U-sutures were placed in the right atrial free wall and the stitches brought through all layers of Teflon strips and HeartWare ring.

After partial clamping of the main pulmonary trunk, a diamond-shaped anastomosis was created with the outflow graft. The inflow cannula was implanted into the right atrium through the augmented ring. A Gore Tex patch was sutured to to the native pericardium creating space to accommodate the pump while preventing future lung 
adhesions.

Adaptions to the lower afterload in the pulmonary circulation are achieved by narrowing the outflow graft. In addition, a lower rotation speed is desirable. Each pump has a different range of rotation speed for optimal performance. The recommended pump speed for the HeartWare device used in this case, is 2,200-3,500 rpm and the outflow graft luminal diameter was narrowed from 10 to $6-7 \mathrm{~mm}$ diameter. The HeartMate 3 pump is fully magnetically levitated, and a low rotation speed can be safely used, narrowing of the outflow graft for this pump is not required.

Depending on the pulmonary vascular resistance, the afterload is increased until a steady state of near equalization of rpm of the right and left pumps with a similar flow is achieved. Once the degree of outflow graft narrowing is determined, a definitive diameter reduction is performed by placing hemostatic clips in a $35 \mathrm{~mm}$ curved line, bearing in mind the Young-Laplace equation. Prior to clip placement, a second piece of vascular graft is wrapped around the outflow graft for protection. The number and position of the clips can then be altered.

\section{Completion}

After chest closure and before leaving the operating theatre, flow changes should be assessed and any problems resolved.

\section{Comments}

\section{Clinical results}

In our institutional report of thirty-nine patients with cfVADs implanted for biventricular support, twentytwo patients received two cfVADs as a primary biventricular assist device, fourteen patients as secondary implantation after temporary RV support, and three patients received a second cfVAD for late RV failure after primary LVAD implantation. Overall thirty-day survival for the group receiving a subsequent pump for $\mathrm{RV}$ support after temporary RV support was $71.4 \%$, and the one-year survival was $40.8 \%$ (1).

Shah et al. reported in a multicenter series of forty-six patients a one-year survival of $74 \%$ in contemporaneous implants and $40 \%$ in staged implants (2). The mortality during the index hospitalization of $33 \%$ matches our slightly lower thirty-day mortality of $28.6 \%$. Comparing outcomes in this very sick patient population is difficult as outcome is driven by indication, timing (primary versus secondary implant) and subsequent rate of transplantation. Shah et al. reported an overall heart transplantation rate of $43 \%$. In our institutional report one of thirty-nine patients received a heart transplant.

Arabía et al. observed RVAD pump thrombosis in 37\% of patients, a rate also seen in an analysis of the INTERMACS database (3). In our report $31 \%$ developed pump thrombosis during a cumulated cfRVAD support time of 106 patientyears (1). Pump thrombosis remains a major long-term complication of biventricular cfVAD (cfBIVAD) therapy (4).

While these results are clearly suboptimal potential alternative treatments also have major limitations. Analysis of the INTERMACS database between 2012 and 2014 report a one year survival for BIVAD of $56 \%$ and for TAH of $59 \%$ (5). Two further possibilities for biventricular support are pulsatile paracorporeal flow pumps and total artificial hearts (TAH). Fully implanted cfLVAD's showed in a randomized control trial not only better survival but a higher quality of life, as measured by the Minnesota Living with Heart Failure questionnaire compared to a pulsatileflow device (6). The idea of offering this advantage using two fully implantable VADs led to the concept of cfBIVAD.

The HeartWare and Heartmate 3 are the most implanted and studied devices for cfLVAD support. Both pumps have been implanted for RV support. The main difference is the size of the pump and in adults both pumps can usually be implanted. From a technical perspective combinations, for example left side Heartmate 3 and right side HeartWare, are possible and have been used. However they should be avoided in primary cfBIVAD implants because the patient must manage two different controllers. HeartWare in a BIVAD configuration has been used in infants (with a body surface area between $0.6-1.9 \mathrm{~m}^{2}$ ) and older patients with congenital heart disease $(7,8)$.

\section{Caveats}

Pump thrombosis is a major concern for long-term use of cfVAD for RV support. An analysis of the INTERMACS database showed a high rate of suspected pump thrombosis for the right-sided pump in BIVAD configurations (3). Smaller reports show a lower rate of pump thrombosis for right atrial compared to RV configuration (4). Heart tumors and large ventricular septal defect are better treated with TAH if the patient can accommodate the pump size. Heart failure in patients with single ventricle can be treated in 
selected cases with cfBIVAD after surgical separation of the pulmonary and systemic circulation (8).

\section{Acknowledgments}

Funding: None.

\section{Footnote}

Conflicts of Interest: The authors have no conflicts of interest to declare.

Open Access Statement: This is an Open Access article distributed in accordance with the Creative Commons Attribution-NonCommercial-NoDerivs 4.0 International License (CC BY-NC-ND 4.0), which permits the noncommercial replication and distribution of the article with the strict proviso that no changes or edits are made and the original work is properly cited (including links to both the formal publication through the relevant DOI and the license). See: https://creativecommons.org/licenses/by-nc-nd/4.0/.

\section{References}

1. Eulert-Grehn JJ, Lanmüller P, Schönrath F, et al. Two implantable continuous-flow ventricular assist devices in a biventricular configuration: technique and results. Interact

Cite this article as: Eulert-Grehn JJ, Lanmüller P, Starck C, Hennig F, Jacobs S, Falk V, Potapov E. Continuous-flow biventricular mechanical support implantation strategies. Ann Cardiothorac Surg 2021;10(3):408-410. doi: 10.21037/acs2021-cfmcs-36
Cardiovasc Thorac Surg 2018;27:938-42.

2. Shah P, Ha R, Singh R, et al. Multicenter experience with durable biventricular assist devices. J Heart Lung Transplant 2018;37:1093-101.

3. Arabía FA, Milano CA, Mahr C, et al. Biventricular Support With Intracorporeal, Continuous Flow, Centrifugal Ventricular Assist Devices. Ann Thorac Surg 2018;105:548-55.

4. Shehab S, Macdonald PS, Keogh AM, et al. Long-term biventricular HeartWare ventricular assist device support-Case series of right atrial and right ventricular implantation outcomes. J Heart Lung Transplant 2016;35:466-73.

5. Kirklin JK, Naftel DC, Pagani FD, et al. Seventh INTERMACS annual report: 15,000 patients and counting. J Heart Lung Transplant 2015;34:1495-504.

6. Slaughter MS, Rogers JG, Milano CA, et al. Advanced heart failure treated with continuous-flow left ventricular assist device. N Engl J Med 2009;361:2241-51.

7. Schweiger M, E Mascio C, Kanter KR, et al. Intracorporeal Biventricular Assist Devices Using the Heartware Ventricular Assist Device in Children. ASAIO J 2020;66:1031-4.

8. Ovroutski S, Miera O, Krabatsch T, et al. Two Pumps for Single Ventricle: Mechanical Support for Establishment of Biventricular Circulation. Ann Thorac Surg 2017;104:e143-e145. 